\title{
Mechanism and Kinetics of Thermal Embrittlement of Austenitic Chromium-Nickel Steel during Long-Term High-Temperature Holding
}

\author{
Kirill A. Okhapkin \\ NRC "Kurchatov Institute" - CRISM "Prometey", 49 Shpalernaya str., St. Petersburg, Russia, \\ 191015 \\ kirill.okhapkin@mail.ru
}

Keywords: Austenitic Steel, Thermal Embrittlement, Mechanism, High-Temperature Holding

\begin{abstract}
This article describes a model of structural changes in austenitic chromium-nickel steel during long-term thermal soakings. The time for reaching equilibrium content of $\mathrm{Cr}_{23} \mathrm{C}_{6}$ carbide at a temperature of $600{ }^{\circ} \mathrm{C}$ is calculated. The calculation results are compared with experimental data on the kinetics of thermal embrittlement of steel at a temperature of $600{ }^{\circ} \mathrm{C}$ after thermal holding for up to 15000 hours.
\end{abstract}

\section{Introduction}

Long-term high-temperature operation under conditions of high diffusion mobility of alloying elements in steel leads to changes in the structure and, as a consequence, in the mechanical properties of structural materials. Periodic destructive testing of equipment elements of reactor facilities makes it possible to assess the residual level of properties at the time of testing. To be able to predict the level of mechanical properties during further operation (after destructive testing), it is necessary to predict the structural and phase transformations occurring in the material.

The purpose of this work is a computational and experimental assessment of the kinetics of the process of structural transformations and thermal embrittlement in austenitic steel grade 09Cr18Ni9 during long-term high-temperature holding.

\section{Mechanism of thermal embrittlement and a description of the calculation model}

To describe the mechanism of thermal embrittlement, it is necessary to establish the relationship of structural changes with a decrease in the characteristics of impact toughness over time.

Secondary phases in steel grade $09 \mathrm{Cr} 18 \mathrm{Ni} 9$ during long-term high-temperature holding are formed in the following order. First, due to the limited solubility of carbon, it is released from the solid solution with the formation of chromium carbide $\mathrm{Cr}_{23} \mathrm{C}_{6}$. This leads to the formation of areas with a low chromium content near the carbide precipitates. It is known [1] that chromium with its content in steel $\sim 17 \%$ in combination with nickel, in contrast to its usual ferritizing action, strongly contributes to the formation of an austenitic structure as a result of complex interatomic interaction. Therefore, in zones depleted in chromium, austenite is transformed into ferrite $(\alpha)$. In this case, the excess nickel content by diffusion can pass into the forming G-phase.

To confirm the stated mechanism, an experiment was carried out on a metal with different carbon content: 0.07 and 0.09 wt. \%. The samples were exposed to heat holding for various durations at a temperature of $600{ }^{\circ} \mathrm{C}$, during aging, the content of the $\alpha$-phase was determined (Fig. 1). In the material with a carbon content of $0.07 \%$, the $\alpha$-phase was formed significantly less, which confirms the relationship between the precipitation of chromium carbide and the formation of the $\alpha$-phase, since at a carbon content of 0.07 and 0.09 wt. $\%$, the amount of $\mathrm{Cr}_{23} \mathrm{C}_{6}$ at a 
temperature of $600^{\circ} \mathrm{C}$ in an equilibrium state according to the data of thermodynamic modeling is also significantly different and amounts to 0.87 and $1.57 \mathrm{wt}$. \% respectively.

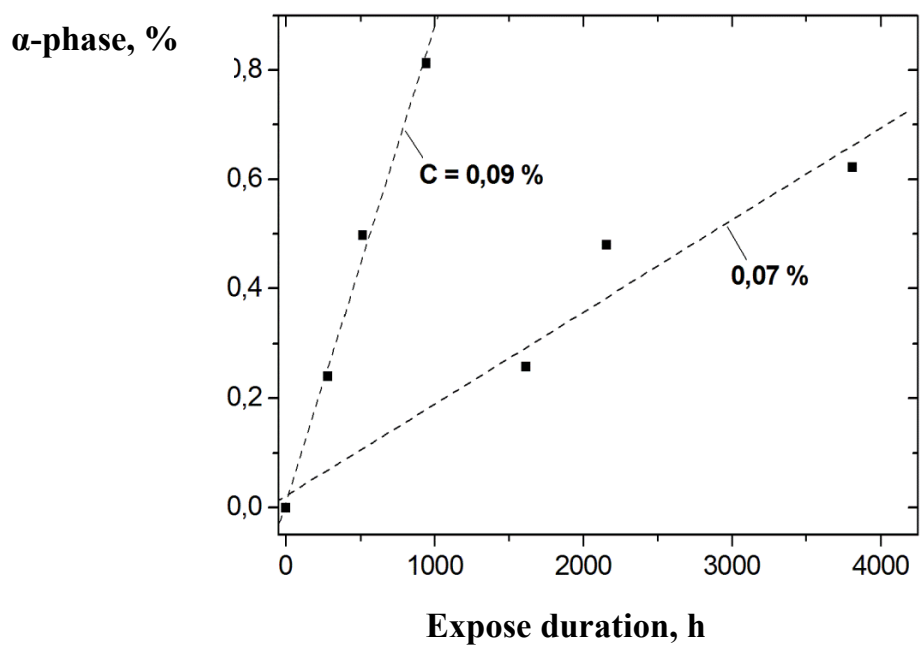

Fig. 1. Influence of carbon content on the kinetics of $\alpha$-phase precipitation at a temperature of $600^{\circ} \mathrm{C}$.

Of the secondary precipitates found in steel, only chromium carbide has an embrittling effect. Therefore, the formation of chromium carbide will determine the kinetics of thermal embrittlement. The formation of particles of the carbide phase will proceed until the equilibrium content is reached at a given temperature. According to the results of thermodynamic modeling, the equilibrium content of $\mathrm{Cr}_{23} \mathrm{C}_{6}$ at a temperature of $600{ }^{\circ} \mathrm{C}$ is $1.57 \%$. Let's assume that all grains in the material structure are spherical and of the same size. Under these conditions, the process of carbide formation in each of the grains will proceed in the same way. In the range of operating temperatures, the carbide phase is formed mainly along the grain boundary. Fig. 2 shows a diagram of the formation of a layer of carbide with a thickness of $\delta$ along the grain boundary $\gamma$ - austenite in the direction $\mathrm{v}$ from the boundary to the center of the sphere.

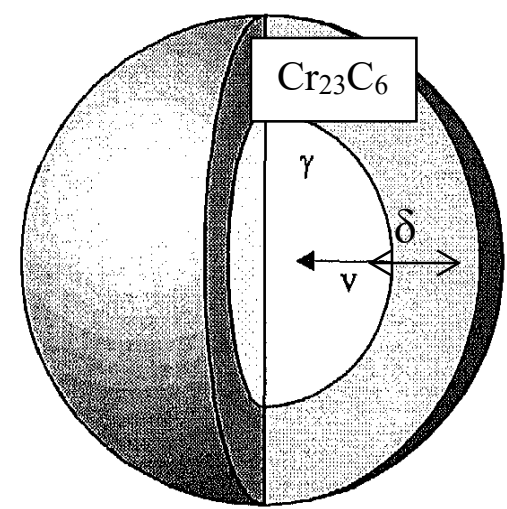

Fig. 2. Scheme of the growth of the carbide phase along the grain boundary of austenite.

The thickness of the carbide layer $\delta$ is related to the volume fraction by the following relationship [2]: 


$$
V^{\kappa}=1-\left(\frac{d_{\gamma}-2 \delta}{d_{\gamma}}\right)^{3}
$$

where $V_{K}$ is the volume fraction of the carbide phase, $d_{\gamma}$ is the austenite grain diameter.

The calculation of the thickness of the layer of the carbide phase at each moment of time can be carried out on the basis of the analysis of the physical and mathematical model of chromium diffusion. A diagram of the growth process of the carbide phase, limited by chromium diffusion, is shown in Figure 3 [3]. There is a transition region between carbide and ferrite, but for simplicity, a sharp phase boundary is assumed in the scheme, at which the chromium concentration changes abruptly from the equilibrium value in ferrite $\left(C_{C r}^{\alpha}\right)$ to a similar value in $\mathrm{Cr}_{23} \mathrm{C}_{6}$ carbide $\left(C_{C r}^{\kappa}\right)$. At a considerable distance from the center of the new phase, the chromium concentration retains its initial value $\left(C_{C r}^{\gamma}\right)$.

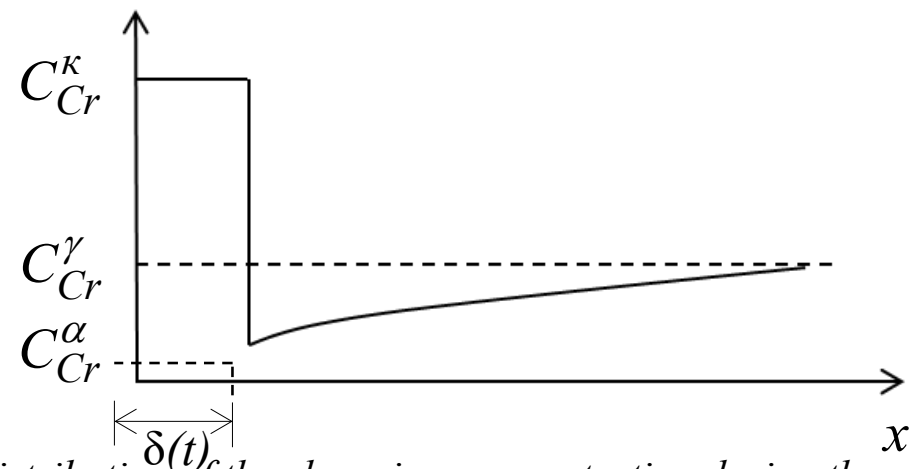

Fig. 3. Schematic distribution of the chromium concentration during the growth of the carbide phase layer [3].

The mathematical formulation of the growth problem for a layer of a new phase is given, for example, in [4]. The redistribution of chromium in the region $\delta(\mathrm{t})<\mathrm{x} \leq \infty$ is described by the diffusion equation:

$$
\frac{1}{D} \frac{\partial C}{\partial t}=\frac{\partial^{2} C}{\partial x^{2}}
$$

with the following boundary conditions:

$$
\lim _{x \rightarrow \infty} C(x, t)=C_{C r}^{\gamma} ; C(\delta(t), t)=C_{C r}^{\alpha} ; C(x, t)=C_{C r}^{\kappa} \text {, at } x<\delta(t) ; \frac{\partial C(\infty)}{\partial x}=0 \text {. }
$$

A mass balance must be observed on the surface of the new phase layer:

$$
\left(C_{C r}^{\kappa}-C_{C r}^{\alpha}\right) \frac{d \delta(t)}{d t}=\left.D \frac{\partial C}{\partial x}\right|_{x=\delta(t)}
$$


Based on the solution of the indicated boundary value problem in [5], an expression was obtained for calculating the thickness of the new phase:

$$
\begin{gathered}
\delta(t)=2 \frac{\left(C_{C r}^{\gamma}-C_{C r}^{\alpha}\right)}{\left(C_{C r}^{\kappa}-C_{C r}^{\alpha}\right)} \sqrt{\frac{D t}{\pi}} \\
t_{p}=\frac{\pi}{D}\left(\frac{d_{\gamma}\left(1-\sqrt[3]{1-V^{\kappa}}\right)}{2 \frac{C_{2 p}-C_{C r}^{\gamma}}{C_{C r}^{\kappa}-C_{2 p}}}\right)^{2}
\end{gathered}
$$

\section{Results and discussion}

For the calculation, the following values of the parameters included in the expression (5): $D_{C r}=$ $8,1^{*} 10^{-20} \mathrm{~m}^{2} \mathrm{~s}^{-1}[6] ; d_{\gamma}=66,5 \mu \mathrm{m} ; C_{C r}^{\gamma}=14,76 \% ; C_{2 p}=0,1^{*} C_{C r}^{\gamma}=1,476 \% ; C_{C r}^{\kappa}=81,95 \%$. The time to reach the equilibrium content of $\mathrm{Cr}_{23} \mathrm{C}_{6}$ carbide at a temperature of $600{ }^{\circ} \mathrm{C}$, according to the calculation results, was 12164 hours. To verify the calculated data, an experiment was carried out, during which thermal soakings were carried out at a temperature of $600{ }^{\circ} \mathrm{C}$ for various durations, followed by determination of the impact toughness (Figure 4). The cessation of the precipitation of the $\mathrm{Cr}_{23} \mathrm{C}_{6}$ carbide leads to the stabilization of the values of the impact toughness. According to the calculation data, the time to reach the equilibrium carbide content is $12164 \mathrm{~h}$, according to the experimental data, the thermal embrittlement process is stabilized at a holding time of $11000 \mathrm{~h}$. Thus, the calculation results are in good agreement with the experimental data, the discrepancy is $11 \%$, while the calculated estimate shows a longer value of time reaching an equilibrium content of the carbide phase, therefore, it is conservative.

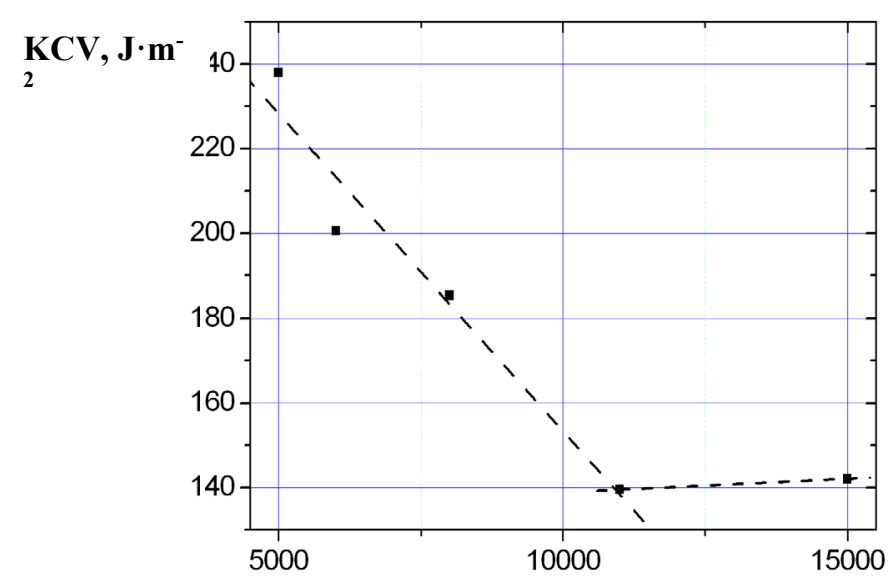

Fig. 4. Thermal embrittlement of $09 \mathrm{Cl}$

Expose duration, $\mathbf{h}$, iolding at a temperature of $600^{\circ} \mathrm{C}$.

\section{Summary}

The time for reaching equilibrium content of $\mathrm{Cr}_{23} \mathrm{C}_{6}$ carbide at a temperature of $600{ }^{\circ} \mathrm{C}$ is calculated. According to the calculation data, the time to reach the equilibrium carbide content is $12164 \mathrm{~h}$, according to the experimental data, the thermal embrittlement process is stabilized at a holding time of $11000 \mathrm{~h}$. Thus, the calculation results are in good agreement with the experimental data, the discrepancy is $11 \%$, while the calculated estimate shows a longer value of time reaching an equilibrium content of the carbide phase, therefore, it is conservative. 


\section{Acknowledgements}

Experimental studies were carried out on the equipment of the Core shared research facilities "Composition, structure and properties of structural and functional materials" of the NRC «Kurchatov Institute» - CRISM "Prometey" with the financial support of the state represented by the Ministry of Education and Science of the Russian Federation under agreement No. 13.CKP.21.0014 (075-11-2021-068). The unique identifier is RF----2296.61321X0014.

\section{References}

[1] Basics of alloying steel. Meskin V.S. Moscow, State Scientific and Technical Publishing House of Literature on Ferrous and Non-Ferrous Metallurgy, 1959. - 688 p.

[2] Y. van Leeuwen, J. Sietsma, S. Vooijs, S. van der Zwaag Effect of the Geometry in Modelling the Kinetics of Diffusional Transformations in Substitutional Iron Alloys // Proceedings from Materials Solutions '97 on Acceleraed Cooling/Direct Quenching Steels 15-18 September 1997, Indianapolis, Indiana, p. 59 - 66.

[3] Formation of chemical microheterogeneity in cast alloys. G.P. Anastasiadi. - SPb.: Polytechnic, 1991. - 148 p.

[4] Lyubov B.Ya. Diffusion processes in inhomogeneous solid media. - M.: Science. Main edition of physical and mathematical literature, 1981.

[5] A.I. Rudskoy, G.P. Anastasiadi, A.S. Oryshchenko, S.Yu. Kondratyev, M.D. Fuchs Features of structural changes in heat-resistant alloy $45 \mathrm{Cr} 26 \mathrm{Ni} 33 \mathrm{Si} 2 \mathrm{Nb} 2$ at operating temperatures. Message 3: Mechanism and kinetics of phase transformations // Scientific and technical bulletin of SPbSPU. Science and education 3 - 2'2012, p. 143 - 150.

[6] Shao Bo Ping, Fei Xie, Rui Kun Wang, Zhi Jun Zheng, Yan Gao Diffusion Kinetics of Chromium in a Novel Super304H Stainless Steel // High Temperature Materials and Processes, 2017, Volume 36, Issue 2, pp. 175 - 181. https://doi.org/10.1515/htmp-2015-0227 